\title{
Carbon Dioxide Water Bathing Enhances Myogenin but Not MyoD Protein Expression after Skeletal Muscle Injury
}

\author{
Koj Nonaka $^{1)^{*}}$, Junichi Akiyama ${ }^{2)}$, Naomi Tatsuta ${ }^{2)}$, Satsuki Une $^{3)}$, Kenichi Ito $^{1)}$, \\ Shinya Ogaya ${ }^{1)}$, Masataka Kataoka ${ }^{1)}$, Akira Imata ${ }^{1)}$, Kuniharu Okuda ${ }^{1)}$ \\ 1) Department of Physical Therapy, Osaka Prefecture University: 3-7-30 Habikino, Habikino-shi, \\ Osaka 583-8555, Japan. TEL: +81 72-950-2111, FAX: +81 72-950-2130 \\ 2) Research Institute of Health Welfare, Kibi International University \\ 3) Department of Living Science, Shujitsu Junior College
}

\begin{abstract}
Purpose] We reported that carbon dioxide $\left(\mathrm{CO}_{2}\right)$ water bathing accelerates skeletal muscle regeneration; however, the underlying mechanism was unclear. MyoD and myogenin play roles in muscle regeneration, and the purpose of this study was to determine changes in $\mathrm{MyoD}$ and myogenin caused by $\mathrm{CO}_{2}$ water bathing after injury. [Subjects] Sixteen female Wistar rats $(n=4$ per group) were used. [Methods] The rats were divided into four groups: no-injury (NI), injury (IC), injury + tap water bathing (ITW), and injury $+\mathrm{CO}_{2}$ water bathing $\left(\mathrm{ICO}_{2}\right)$. Muscle injury was induced by injection of bupivacaine hydrochloride into the left tibial anterior (TA) muscles. Tap water and $\mathrm{CO}_{2}(1,000 \mathrm{ppm})$ water bathing were performed at $37^{\circ} \mathrm{C}$ for 30 minutes once a day. The left TA muscles were removed 4 days after injury, and the expressions of MyoD and myogenin were measured. [Results] MyoD and myogenin were increased in the IC, ITW, and $\mathrm{ICO}_{2}$ groups compared with the NI group. Although the MyoD level was similar in the IC, ITW, and $\mathrm{ICO}_{2}$ groups, myogenin increased more in the $\mathrm{ICO}_{2}$ group than in the IC and ITW groups. [Conclusion] $\mathrm{CO}_{2}$ water bathing after muscle injury appears to induce an increase in the expression of myogenin.

Key words: Skeletal muscle injury, $\mathrm{CO}_{2}$ water bathing, Myogenic regulatory factors
\end{abstract}

(This article was submitted Dec. 28, 2012, and was accepted Feb. 8, 2013)

\section{INTRODUCTION}

Carbon dioxide $\left(\mathrm{CO}_{2}\right)$ water bathing has a long history in European countries and has been used to treat cardiovascular disease since the Middle Ages. $\mathrm{CO}_{2}$ water bathing is a kind of remedy with a wide spectrum of applications. $\mathrm{CO}_{2}$ water bathing results in vasodilatation and an increase in blood flow ${ }^{1,2)}$. The vasodilatation is induced by $\mathrm{CO}_{2}$, which diffuses into the subcutaneous tissue through the skin. $\mathrm{CO}_{2}$ water bathing has been reported to have several positive physiological effects. For example, $\mathrm{CO}_{2}$ water bathing enhanced VEGF mRNA levels, resulting in neovascularization in ischemic hindlimbs of mice ${ }^{3)}$. In our previous study, we investigated whether $\mathrm{CO}_{2}$ water bathing accelerates skeletal muscle repair after injury ${ }^{4}$.

Skeletal muscle has the ability to regenerate new muscle fibers after injury. Satellite cells are muscle stem cells and play an important role in skeletal muscle fiber repair after injury. Satellite cells proliferate, differentiate into myoblasts expressing muscle-specific proteins, fuse into myotubes, and finally mature into myofibers ${ }^{5}$. Satellite cells are normally in a quiescent state, but they are activated when skeletal muscle fibers are injured. The activated

${ }^{*}$ To whom correspondence should be addressed.

E-mail: nonaka@rehab.osakafu-u.ac.jp satellite cells proliferate, differentiate, and fuse to repair injured skeletal muscle fibers. Myogenic regulatory factors (MRFs), including MyoD, Myf5, myogenin, and MRF4, are transcription factors that control the expression of several muscle genes. The myogenic basic helix-loop-helix (bHLH) family of transcription factors are thought to play an important role in the development and regeneration of skeletal muscle ${ }^{6}$, and MRFs regulate the complex phenomenon of myogenic differentiation.

As noted above, MRFs play an important role in skeletal muscle regeneration, but MyoD and myogenin were not increased by $\mathrm{CO}_{2}$ water bathing at 2 weeks after injury in our previous study ${ }^{4}$. Therefore, the mechanism underlying the acceleration of skeletal muscle regeneration induced by $\mathrm{CO}_{2}$ water bathing was unclear. The expression of MRFs is observed in the early stage of regeneration after skeletal muscle injury. We hypothesized that $\mathrm{CO}_{2}$ water bathing increases the expression of $\mathrm{MyoD}$ and myogenin in early stage of regeneration after injury, since the expression of MyoD and myogenin proteins was observed in a morphological study at 4 days after skeletal muscle injury ${ }^{7}$. Thus, the purpose of this study was to examine the effect of $\mathrm{CO}_{2}$ water bathing on the expression of MyoD and myogenin in injured muscles at 4 days after skeletal muscle injury. 


\section{SUBJECTS AND METHODS}

Sixteen female Wistar rats (224-282 g) were used in this study. The rats were housed in a temperature controlled room, $22{ }^{\circ} \mathrm{C}$, on a $12 \mathrm{~h}: 12 \mathrm{~h}$ light-dark cycle, and were allowed free access to food and water. The rats were assigned to no-injury (NI, $n=4)$, injury ( $\mathrm{IC}, \mathrm{n}=4)$, injury + tap water bathing (ITW, $n=4)$, and injury $+\mathrm{CO}_{2}$ water bathing $\left(\mathrm{ICO}_{2}\right.$, $\mathrm{n}=4$ ) groups. The rats in the $\mathrm{IC}$, ITW, and $\mathrm{ICO}_{2}$ groups were anesthetized by injection of pentobarbital sodium $(50 \mathrm{mg}$ / $\mathrm{kg}$ ); then, the left tibial anterior (TA) muscle was injured by injection of $0.3 \mathrm{~mL}$ of $0.5 \%$ bupivacaine hydrochloride (Marcaine, AstraZeneca, Osaka, Japan) using a disposable syringe with a 27 -gauge needle. The needle was inserted into the mid-belly portion of the TA muscle and advanced longitudinally to the proximal portion. The solution was injected as the needle was withdrawn slowly as described previously ${ }^{4}$. One day after the TA muscle injury, rats in the ITW, and $\mathrm{ICO}_{2}$ groups were immersed in tap water and $\mathrm{CO}_{2}$ water $\left(\mathrm{CO}_{2}\right.$ concentration; $\left.1,000 \mathrm{ppm}\right)$, respectively, at $37^{\circ} \mathrm{C}$, for 30 minutes once a day for 3 consecutive days. $\mathrm{CO}_{2}$ water containing a high concentration of $\mathrm{CO}_{2}$ was made from high pressure $\mathrm{CO}_{2}$ in a cylinder and tap water using an MRE-Spa (Mitsubishi Rayon Co., Ltd., Tokyo, Japan). Four days after injury, the rats were sacrificed by injection of an overdose of sodium pentobarbital and their left TA muscles were removed. The TA muscles were immediately frozen in isopentane cooled by liquid nitrogen and stored at $-80^{\circ} \mathrm{C}$ until analysis. All procedures were approved by the Animal Care and Use Committee of Kibi International University.

For the analysis of the expression of MyoD and myogenin, the muscles were homogenized in Tris- $\mathrm{HCl}(\mathrm{pH} 7.4)$. After centrifugation, the supernatant was collected as the measurement sample. The protein concentrations of these samples were measured using the Bradford method and a Coomassie Protein Assay Kit (Thermo Fisher Scientific K.K., Kanagawa, Japan). The samples were added to EzApply (ATTO, Tokyo, Japan), adjusted to a final protein concentration of $1 \mu \mathrm{g} / \mu \mathrm{l}$, and then boiled at $95{ }^{\circ} \mathrm{C}$ for 5 minutes. We then applied $10 \mu \mathrm{g}$ protein to a $12.5 \%$ polyacrylamide gel (ATTO, Tokyo, Japan). Electrophoresis was carried out at a constant current of $20 \mathrm{~mA} /$ gel for 60 minutes, and proteins were then transferred to a polyvinylidene difluoride (PVDF) membrane using a HorizBLOT $2 \mathrm{M}$ (ATTO, Tokyo, Japan) at a constant current of $2 \mathrm{~mA} / \mathrm{cm}^{2}$ for 60 minutes. Following blots, the PVDF membrane was then incubated for 60 minutes using EzBlot (ATTO, Tokyo, Japan). The membrane was then incubated with a monoclonal antibody for MyoD (Santa Cruz Biotechnology, Santa Cruz, CA, USA) diluted 1:2,000 with $0.1 \mathrm{M}$ Tris- $\mathrm{HCl}$ (pH
7.5) or myogenin (Santa Cruz Biotechnology, Santa Cruz, CA, USA) diluted 1:2,000 with $0.1 \mathrm{M}$ Tris- $\mathrm{HCl}(\mathrm{pH} 7.5)$ for 1 hour at room temperature. The membrane was washed 3 times in $0.1 \mathrm{M}$ Tris- $\mathrm{HCl}$ with $0.1 \%$ Tween-20 and then reacted with anti-mouse IgG (Nacalai tesque, Kyoto, Japan) diluted 1:10,000 with $0.1 \mathrm{M}$ Tris- $\mathrm{HCl}(\mathrm{pH} 7.5)$ for 1 hour at room tempareture. The membrane was washed 3 times a further in $0.1 \mathrm{M}$ Tris- $\mathrm{HCl}$ with $0.1 \%$ Tween-20 and then reacted with EzWestBlue (ATTO, Tokyo, Japan). Bands from western blots were quantified using the ImageJ software (NIH, Bethesda, MD, USA).

Data are expressed means \pm SD and were analyzed by one-way ANOVA. When there were significant differences, the Tukey post hoc test was used to determine differences between the groups. Statistical analyses were performed using Excel Statistics 2008 (Social Survey Research Information Co., Ltd., Tokyo, Japan). Statistical significance was accepted for values of $\mathrm{p}<0.05$.

\section{RESULTS}

Our results are shown in Table 1. The MyoD level was significantly higher in the IC, ITW, and $\mathrm{ICO}_{2}$ groups than in the NI group $(p<0.01)$. However, there were no significant differences among the IC, ITW, and $\mathrm{ICO}_{2}$ groups. The myogenin level was significantly higher in the IC, ITW, and $\mathrm{ICO}_{2}$ groups than in the NI group $(\mathrm{p}<0.01)$. In addition, the myogenin level was significantly higher in the $\mathrm{ICO}_{2}$ group than in the NI and ITW groups ( $<<0.05)$, but there was no significant difference in its level between the IC and ITW groups.

\section{DISCUSSION}

In the present study, $\mathrm{CO}_{2}$ water bathing increased the expression of myogenin, but not the expression of MyoD. This result indicates that $\mathrm{CO}_{2}$ water bathing accelerates skeletal muscle regeneration via an increase in the expression of myogenin.

MyoD and myogenin are transcription factors belonging to the bHLH family of transcription factors. These proteins play important roles in satellite cell proliferation, differentiation, fusion, and the formation of myocytes. MyoD has a critical role in skeletal muscle regeneration via activation of satellite cells ${ }^{8)}$. Cooper et al. observed that MyoD is expressed in myotubes with centrally located myonuclei at 5 days after cardiotoxin injection ${ }^{9)}$. They also suggested that MyoD is required for proliferation and differentiation of activated satellite cells during the regeneration of skeletal muscle fibers. Myotube formation is delayed in regenerating skeletal muscle in the absence of $\mathrm{MyoD}^{10)}$, indicating

Table 1. The expression of MyoD and myogenin

\begin{tabular}{lcccl}
\hline & NI $(n=4)$ & IC $(n=4)$ & ITW $(n=4)$ & ICO $_{2}(\mathrm{n}=4)$ \\
\hline MyoD (\% of NI) & $100 \pm 13^{*}$ & $224 \pm 16^{*}$ & $220 \pm 23^{*}$ & $212 \pm 20^{*}$ \\
myogenin (\% of NI) & $100 \pm 24 *$ & $174 \pm 23^{*}$ & $171 \pm 27^{*}$ & $226 \pm 11^{*}, \#, \dagger$ \\
\hline
\end{tabular}

Values are means $\pm \mathrm{SD}, *$; different from NI, $\mathrm{p}<0.01$. \#; different from IC, $\mathrm{p}<0.05$. $\dagger$; different from ITW, $\mathrm{p}<0.05$ 
that MyoD plays an important role in myotube formation in regenerating skeletal muscle. In experiments using knockout mice, MyoD and Myf5 were shown to have roles in the determination of the myogenic cell fate and the formation of myoblasts during embryogenesis, and myogenin and MRF4 were shown to have roles in the activation of muscle differentiation $^{11,12)}$. In addition, newborn mice deficient for both MyoD and Myf5 are devoid of myoblasts ${ }^{6}$, and myogenin $(-/-)$ mice form myoblasts that fail to form myotubes ${ }^{13)}$. In the present study, we observed an increase in MyoD in the groups with skeletal muscle injury. Activation of satellite cells and myoblast formations occurred normally in the injured skeletal muscle fibers in the groups with skeletal muscle injury, and the increase in MyoD was similar in the IC, ITW, and $\mathrm{ICO}_{2}$ groups. These data suggest that $\mathrm{CO}_{2}$ water bathing did not affect the expression of $\mathrm{MyoD}$, indicating that $\mathrm{CO}_{2}$ water bathing does not accelerate myoblast formation via activation of satellite cells. An increase in myogenin was also observed in the groups with skeletal muscle injury. Myotube formation occurred normally in the groups with skeletal muscle injury; however, the increase in myogenin was greater in the $\mathrm{ICO}_{2}$ group than in the IC and ITW groups. This result indicates that $\mathrm{CO}_{2}$ water bathing affects the expression of myogenin, and might accelerate fusion of myoblasts and formation of myotubes. In our previous study, $\mathrm{CO}_{2}$ water bathing increased myonuclei in regenerating skeletal muscle fibers at 2 weeks after skeletal muscle injury. Taken together, these results indicate that $\mathrm{CO}_{2}$ water bathing accelerates skeletal muscle fiber regeneration via increase in the expression of myogenin enhancing the fusion of myoblasts. Nitric oxide (NO) is a key signal responsible for satellite cell activation and hepatocyte growth factor (HGF), which is an activator of satellite cells, is released from the extracellular matrix after skeletal muscle injury ${ }^{14)}$. Tatsumi et al. reported that activation of satellite cells and HGF release in stretched muscle were dependent on local $\mathrm{NO}$ production ${ }^{15)}$. Irie et al. reported that $\mathrm{CO}_{2}$ water bathing increased in phosphorylated NO synthase in ischemic skeletal muscle ${ }^{3)}$, indicating that $\mathrm{CO}_{2}$ water bathing promotes NO production in skeletal muscle. Although no measure of NOS was included in the present study, we speculate that $\mathrm{NO}$ production in skeletal muscle was promoted by $\mathrm{CO}_{2}$ water bathing. $\mathrm{NO}$ might increase myogenin expression and promote skeletal muscle regeneration.
A number of factors are related to skeletal muscle regeneration. MyoD and myogenin are two factors regulating skeletal muscle regeneration. Further studies are needed to determine more clearly the mechanisms which accelerate skeletal muscle fiber regeneration in $\mathrm{CO}_{2}$ water bathing.

\section{REFERENCES}

1) Schnizer $\mathrm{W}$, Erdl $\mathrm{R}$, Schops $\mathrm{P}$, et al.: The effects of external $\mathrm{CO}_{2}$ application on human skin microcirculation investigated by laser Doppler flowmetry. Int J Microcirc Clin Exp, 1985, 4: 343-350. [Medline]

2) Ito T, Moore JI, Koss MC: Topical application of $\mathrm{CO}_{2}$ increases skin blood flow. J Invest Dermatol, 1989, 93: 259-262. [Medline] [CrossRef]

3) Irie $\mathrm{H}$, Tatsumi $\mathrm{T}$, Takamiya $\mathrm{M}$, et al.: Carbon dioxide-rich water bathing enhances collateral blood flow in ischemic hindlimb via mobilization of endothelial progenitor cells and activation of NO-cGMP system. Circulation, 2005, 111: 1523-1529. [Medline] [CrossRef]

4) Nonaka K, Akiyama J, Tatsuta N, et al.: Carbon dioxide-rich water bathing increases myonuclear number and muscle fiber size in regenerating skeletal muscles. J Phys Ther Sci, 2012, 24: 1295-1298. [CrossRef]

5) Rantanen J, Hurme T, Lukka R, et al.: Satellite cell proliferation and the expression of myogenin and desmin in regenerating skeletal muscle: evidence for two different populations of satellite cells. Lab Invest, 1995, 72: 341-347. [Medline]

6) Rudnicki MA, Schnegelsberg PN, Stead RH, et al.: MyoD or Myf-5 is required for the formation of skeletal muscle. Cell, 1993, 75: 1351-1359. [Medline] [CrossRef]

7) Füchtbauer EM, Westphal H: MyoD and myogenin are coexpressed in regenerating skeletal muscle of the mouse. Dev Dyn, 1992, 193: 34-39. [Medline] [CrossRef]

8) Megeney LA, Kablar B, Garrett K, et al.: MyoD is required for myogenic stem cell function in adult skeletal muscle. Genes Dev, 1996, 10: 11731183. [Medline] [CrossRef]

9) Cooper RN, Tajbakhsh S, Mouly V, et al.: In vivo satellite cell activation via Myf5 and MyoD in regenerating mouse skeletal muscle. J Cell Sci, 1999, 112: 2895-2901. [Medline]

10) Huijbregts J, White JD, Grounds MD: The absence of MyoD in regenerating skeletal muscle affects the expression pattern of basement membrane, interstitial matrix and integrin molecules that is consistent with delayed myotube formation. Acta Histochem, 2001, 103: 379-396. [Medline] [CrossRef]

11) Rawls A, Wilson-Rawls J, Olson EN: Genetic regulation of somite formation. Curr Top Dev Biol, 2000, 47: 131-154. [Medline] [CrossRef]

12) Smith $\mathrm{TH}$, Block NE, Rhodes SJ, et al.: A unique pattern of expression of the four muscle regulatory factor proteins distinguishes somitic from embryonic, fetal and newborn mouse myogenic cells. Development, 1993, 117: 1125-1133. [Medline]

13) Hasty P, Bradley A, Morris JH, et al.: Muscle deficiency and neonatal death in mice with a targeted mutation in the myogenin gene. Nature, 1993, 364: 501-506. [Medline] [CrossRef]

14) Filippin LI, Moreira AJ, Marroni NP, et al.: Nitric oxide and repair of skeletal muscle injury. Nitric Oxide, 2009, 21: 157-163. [Medline] [CrossRef]

15) Tatsumi R, Liu X, Pulido A, et al.: Satellite cell activation in stretched skeletal muscle and the role of nitric oxide and hepatocyte growth factor. Am J Physiol Cell Physiol, 2006, 290: C1487-C1494. [Medline] [CrossRef] 